\title{
Leadership in the COVID-19 environment: Coping with uncertainty to support PSP mental health
}

\author{
Ronald D. Camp II*
}

In the context of the current COVID-19 health crisis, the public is becoming aware of the reality, if not the concept, of a VUCA (volatile, unknown, complex, and ambiguous) environment. For public safety personnel (PSP), VUCA is the normal context. In the COVID-19 environment, though, PSP seem to be dealing with VUCA on steroids.

An acronym coined by the US Army War College in 1987 (USAHEC, 2018), VUCA is used as a shorthand to quickly describe operational environments that are volatile, unknown, complex, and ambiguous. In a VUCA environment, organizational decision-makers are dealing with situations that change in rapid and unpredictable ways (volatile), in which critical information is unavailable (unknown), in which elements of the environment are many and interdependent, interacting in often unpredictable ways (complex), and that offer unclear action preferences and priorities (ambiguous) (O'Driscoll, 2019). VUCA environments, in turn, create uncertainty for individuals. This uncertainty pertains to the current state of the environment; the range of responses that might be available, appropriate, or desirable for a decisionmaker in that environment; and uncertainty about what outcomes or effects might result from the actions actually taken (Milliken, 1987).

We see this uncertainty playing out on a daily basis for first responders. Randy Mellow, Chief of the Peterborough Paramedic Service and President of the Paramedic Chiefs of Canada, has referred to the current situation as Schrodinger's Pandemic for first responders: Paramedics need to assume simultaneously that they and their patients are both infected with the virus and not infected but in need of being shielded from the virus. In this environment, standard operating procedures intended to provide the best possible paramedical care to patients have been modified to reduce the potential spread of the disease between patients, paramedics, colleagues, and their families.

Police are facing a similar situation during the pandemic in enforcing laws meant to address the emergency. In a recent article, Torigian points out that, in the current context, police are forced to deal with the questions of whether they have moral authority to enforce extraordinary legal measures and "whether public health knowledge about community safety and well-being is a better guide than older ideas about 'public order"' (2020, p. 26).

Under normal conditions, PSP report substantial difficulties with occupational stressors associated with mental health disorder symptoms (Carleton et al., 2020). These stressors include operational issues, such as exposure to potentially psychologically traumatic events (PPTEs), but also organizational issues, such as leadership style, organizational engagement, and the social environment (Carleton et al., 2020). The types of uncertainty we see being created in this elevated VUCA context can, in turn, increase the probability that PSP will experience anxiety (Brosschot, Verkuil, \& Thayer, 2016) and other operational stress injuries.

The question then is how PSP leadership can support their people in coping with the uncertainty and potential anxiety associated with the current COVID-19 pandemic. One option would be to offer support to PSP coping with elevated anxiety issues associated with the crisis. However, two-thirds of PSP would never, or only as a last resort, access support from PSP leaders (Carleton et al., 2019). At the same time, inconsistent leadership is one of the greatest sources of stress for PSP (Carleton et al., 2020). These findings suggest that it might be more effective for PSP leaders to look at how to support PSP mental health and well-being in VUCA situations before uncertainty and anxiety become problematic. They also suggest that leaders may need help focusing on leadership activities that support mental health and well-being.

Fundamentally, leadership is about three roles, or activity sets: to envision, align, and inspire the people in an organization (Kotter, 2001). Under environmental conditions generating high levels of uncertainty, it is important for leaders to set a consistent set of expectations (a vision) for coping with changing, ambiguous circumstances. This vision needs to explicitly state what the governing values of the public safety organization are and how the new policies, procedures, and actions are believed to be instrumental in helping PSP to deliver on those values. Under VUCA conditions, it is impossible to adequately plan and prepare for all possible contingencies. PSP will have to make the best decisions they can, in the field, with inadequate information, and then adjust their actions as they see the immediate results of their decisions to shape

Correspondence to: Ronald D. Camp II, Hill-Levene Schools of Business, University of Regina, 3737 Wascana Parkway, Regina, SK S4S OA2.

E-mail: Ronald.camp@uregina.ca

To cite: Camp, R.D. (2020). Leadership in the COVID-19 environment: Coping with uncertainty to support PSP mental health. Journal of Community Safety and Well-Being, 5(2), 37-38. https://doi.org/10.35502/jcswb.140

@ Author(s) 2020. Open Access. This work is distributed under the Creative Commons BY-NC-ND license. For commercial re-use, please contact sales@sgpublishing.ca.

gPUBLISHING Published by SG Publishing Inc. CSKA Official publication of the Community Safety Knowledge Alliance. 
the situation in the moment to work towards some kind of acceptable outcome. In this context, mistakes are a given, a part of the process, not something to be avoided. But it is important for PSP, public safety organizations, and the public to ensure that these mistakes are part of a learning process in response to shifting organizational challenges and that this process leads to continuous (or incremental) performance improvement (Schein \& Bennis, 1965, cited in Edmondson \& Lei, 2014) that is consistent with the organization's, and individual PSP's, values.

The next step, given changes in decision and action rules (e.g., PPE procedures or extraordinary legal measures), is for PSP leaders to align PSP to new processes. This alignment comes through two-way discussion of the environment, changes in the environment, what the new decision and action rules are meant to help PSP cope with, and how to implement new processes. PSP and their leaders need to discuss how we expect new procedures to work, but also a range of contingencies for what to do when they don't work the way we first expected them to. They also need to have frequent post-incident reviews to discuss what is or isn't working, why we think that is the case, and what PSP and leadership can do to improve processes and outcomes, reducing uncertainty. These discussions are intended to align PSP to the new processes, but also to provide an opportunity to learn so as to adapt and adjust processes to support the actions of PSP in the field. This type of alignment serves to both reduce the level of uncertainty PSP have to cope with over time, as this frequent communication increases understanding of the environment, and to reduce the uncertainty about how leadership will respond to PSP uncertainty in the field.

These alignment discussions can also be the basis for inspiring PSP. PSP need psychological safety to be able to risk making mistakes in coping with the realities of a VUCA environment, meaning that the interpersonal risk that necessarily accompanies uncertainty and change (Schein \& Bennis, 1965) is minimized (Edmondson \& Lei, 2014). With negative consequences from peers and leaders reduced, individuals in these otherwise uncertain, changing contexts are more likely to feel secure and capable of changing their behaviour in response to shifting organizational challenges (Edmondson \& Lei, 2014). According to Schein (1993), this psychologically safe interaction also "helps people overcome the defensiveness, or learning anxiety, that occurs when they are presented with data that contradict their expectations or hopes" (Edmondson \& Lei, 2014, p. 25). This process further helps PSP to develop confidence in their decision-making and their ability to effectively adapt during the crisis. This confidence in turn creates resilience for PSP to deal with the stress associated with uncertainty.

Leadership is an essential factor in supporting PSP in coping with the factors related to COVID-19 that are challenging PSP's mental health and well-being. The COVID-19 pandemic is creating a more extreme VUCA environment for PSP. This environment is increasing the level of uncertainty that PSP must deal with. Combining this environmental uncertainty with the inherent dangers to the physical and mental health of PSP (e.g., PPTEs) increases the risk of anxiety and other operational stress injuries for PSP. Given that the three primary roles of leadership are geared towards reducing organizational uncertainty and giving subordinates the ability, authority, and support necessary to deal with the volatility and ambiguity of a VUCA environment, it is essential that PSP leaders concentrate on performing these roles, not just to promote organizational effectiveness, but to support the mental health and well-being of PSP during and after the COVID-19 crisis.

\section{CONFLICT OF INTEREST DISCLOSURES}

The author has no conflicts of interest to declare.

\section{AUTHOR AFFILIATIONS}

${ }^{*}$ Associate Professor, Hill-Levene Schools of Business, University of Regina, Regina, SK, Canada; Co-academic Director, ICD/Rotman Directors Education Program, Saskatchewan, Canada; TUAS Fellow, Turku University of Applied Sciences, Turku, Finland.

\section{REFERENCES}

Brosschot, J. F., Verkuil, B., \& Thayer, J. F. (2016). The default response to uncertainty and the importance of perceived safety in anxiety and stress: An evolution-theoretical perspective. Journal of Anxiety Disorders, 41, 22-34. https://doi.org/10.1016/i.janxdis.2016.04.012

Carleton, R. N., Afifi, T. O., Taillieu, T., ... Griffiths, C. T. (2020). Assessing the relative impact of diverse stressors among public safety personnel. International Journal of Environmental Research and Public Health, 17(4), 1234. https://doi.org/10.3390/ijerph17041234

Carleton, R. N., Afifi, T. O., Turner, S., ... Camp, R. D. II. (2019). Mental health training, attitudes towards support, and screening positive for mental disorders. Cognitive Behaviour Therapy, 49(1), 55-73. https://doi.org/10.1080/16506073.2019.1575900

Edmondson, A. C., \& Lei, Z. (2014). Psychological safety: The history, renaissance, and future of an interpersonal construct. Annual Review of Organizational Psychology and Organizational Behavior, 1(1), 2343. https://doi.org/10.1146/annurev-orgpsych-031413-091305

Kotter, J. P. (2001). What leaders really do. Harvard Business Review, 79(11).

Milliken, F. J. (1987). Three types of perceived uncertainty about the environment: State, effect, and response uncertainty. Academy of Management Review, 12(1), 133-143. http://www.jstor.org/ stable/257999

O'Driscoll, T. (2019, Nov. 20). Leadership as a system: circumventing the VUCA Vortex. EFMD Global Focus Magazine. https://www.global focusmagazine.com/leadership-as-a-system-circumventing-thevuca-vortex/.

Schein, E. H. (1993). How can organizations learn faster? The challenge of entering the green room. Sloan Management Review, 34, 85-92.

Torigian, M. (2020). Police leadership during a pandemic. Journal of Community Safety and Well-Being, 5(1), 26-27. https://journalcswb.ca/ index.php/cswb/article/view/126/248

U.S. Army Heritage and Education Center (USAHEC). (2019, May 7). Who first originated the term VUCA (Volatility, Uncertainty, Complexity and Ambiguityl? USAHEC Ask Us a Question. The United States Army War College. Retrieved from http://usawc.libanswers. $\mathrm{com} / \mathrm{faq} / 84869$ 